\title{
Functional Cardiovascular System State of Males in Yakutia Depending on Age
}

\author{
Alla Guryeva ${ }^{1}$, Vilyuya Alekseeva ${ }^{1, *}$, Anastasia Beloborodova ${ }^{2}$, Victoria \\ Pryadeznikova $^{2}$ and Victoria Zakharova ${ }^{2}$ \\ ${ }^{1}$ M.K. Ammosov North-Eastern Federal University, Yakutsk, Russia \\ ${ }^{2}$ Primary healthcare unit of the Ministry of Internal Affairs of Russia in Republic of Sakha (Yakutia), Yakutsk, Russia \\ ${ }^{*}$ Corresponding author. Email: va.alekseeva@s-vfu.ru
}

\begin{abstract}
The purpose of the research was to assess the functional state of the cardiovascular system of men in Yakutia of 22-60 years old (depending on the age group). A morphofunctional survey included 295 men of the first mature age (21-35 years old) and 502 men of the second mature age (36-60 years old). An anthropometric survey and index assessment of the functional state of the cardiovascular system were carried out. A smaller value of body length was established at large values of body weight and BMI in men of second mature age. Overweight and obesity are significantly more commonly recorded in second mature adults. Hemodynamic indicators of second mature men were characterized by higher values of SBP, DBP, mean and pulse pressures, cardiac output. In both groups of men, patients with vagotonia predominate. An index assessment of the cardiovascular system revealed: according to the Kwaas index, $70.5 \%$ of men of the first mature age and $62.5 \%$ of the second mature age had a busy loafers heart; most men surveyed had high values; a low level was recorded in $49.5 \%$ in the first group and $62.5 \%$ in the second group by Robinson's index. A comprehensive assessment of the level of functional state and physical development by Pirogova E.A., men of the second mature age were characterized by lower indicators of the level of functional state and physical development.
\end{abstract}

Keywords: cardiovascular system, morphofunction, anthropometrics, Yakutia

\section{INTRODUCTION}

According to WHO, the pathology of the cardiovascular system is among top three most common diseases. In the Republic of Sakha (Yakutia) in 2019, 328.1 people with circulatory system pathology were registered per 10 thousand population. Among the causes of mortality of the population, the pathology of the circulatory system ranks first, so, according to the territorial department of Federal State Statistics Service (Yakutia), in 2019, 1889 men and 1573 women died of this pathology, the mortality rate per 100 thousand population was 412.7 men and 298.6 women [1].

The increasing rate of morbidity and mortality of men from circulatory system pathology is alarming and needs to improve medical and social measures aimed at preserving and improving the health of the male population [2]. The assessment of the functional state of the human cardiovascular system is the most informative, accessible research method, the wide use of which will reveal the risk group for the development of the pathology of the circulatory system. Early diagnosis and prevention of cardiovascular diseases will help prevent or delay the development of formidable complications [3].

The purpose of research: To assess the functional state of the cardiovascular system of 22-60 years old men in Yakutia (depending on the age group)

\section{MATERIALS AND METHODS}

The research was conducted in polyclinics in Yakutsk. A morphofunctional survey included 797 men 
aged 22 to 60 years old. All examined live in Yakutia permanently. According to the age classification, 295 men belonged to the first period of maturity (21-35 years), 502 men to the second period of maturity (36-60 years) of the human ontogenetic cycle. The average age of the examined men of the first and second maturity was $30.38 \pm 3.10$ years old and $46.16 \pm 5.79$ years old, respectively. Scientific work was carried out after the participants voluntarily signed an informed consent study.

An anthropometric examination was carried out measuring body length and weight. Body length is determined by an anthropometer with $0.1 \mathrm{~cm}$ accuracy, body weight is measured on medical scales with $0.1 \mathrm{~kg}$ accuracy. Body mass index (BMI) was calculated.

$\mathrm{BMI}=\mathrm{MT} / \mathrm{P}^{2}$

Where MT is body weight $(\mathrm{kg}), \mathrm{P}$ is body length (m). Groups with a deficiency, normal, overweight and obesity were established by the value of BMI. The body surface area (BSA) was calculated using the Mosteller formula:

BSA $=\sqrt{ }($ Body length $\times$ Body mass $\div 3600)$

Heart rate (HR) counting was performed palpatorically on the radial artery per 1 minute. Pulse counting was carried out before physical exertion (at rest), immediately after physical exertion and in the fifth minute after exertion. As a physical activity, men were offered a full squat with hands extended forward at a speed of 20 squats per 30 seconds. Systolic (SBP) and diastolic (DBP) blood pressure were measured by Omron M3 Expert HR automatic tonometer $\mathrm{mm} \mathrm{Hg}$. The Pulse Pressure (PP) is calculated by PD formula:

$\mathrm{PD}=\mathrm{SBP}-\mathrm{DBP}$

The average BP was calculated using the formula:

$\mathrm{APmean}=(\mathrm{SBP}-\mathrm{DBP}) / 3+\mathrm{DBP}, \mathrm{mm} \mathrm{Hg}$.

For functional condition assessment of the blood circulatory system of men EC - endurance coefficient by Kwaas formula, ARI - the autonomic regulation index, CPBC - coefficient of profitability of blood circulation, SD - the systolic discharge, $\mathrm{CO}$ - cardiac output, the Robinson's Index (RI), IFC - the index of functional changes, physical condition by E.A. Pirogova were calculated, HI - Heart index [4]. The endurance coefficient was calculated according to the formula:

$\mathrm{KV}=\mathrm{HR} \times 10 /(\mathrm{SBP}-\mathrm{DBP})$, c.u.

The norm indicator is the value from 12 to 16 c.u., the value less than 12 indicates the strengthening of the heart rate activity (cardiovascular system), more than 16 - the heart rate detraining, the autonomic regulation index is determined by the formula:

autonomic regulation index $=$

$=(1-\mathrm{DBP} /$ heart rate $) \times 100$, c.u.

A negative index value means the dominance of the parasympathetic nervous system - vagotonia, and a positive value indicates the predominance of sympathetic - sympathicotonia. The index value equal to zero is regarded as equilibrium in the autonomic nervous system. Coefficient of profitability of blood circulation, was determined by the formula:

coefficient of profitability of blood circulation= $=(\mathrm{SBP}-\mathrm{DBP}) \times \mathrm{HR}$.

The coefficient of profitability of blood circulation, shows the energy consumption of the body on hemodynamics. The systolic discharge characterizes the contractility of the left ventricle myocardium, calculated using the Starr formula:

$\mathrm{SD}=90.97+(0.54 \times \mathrm{PP})-(0.57 \times \mathrm{DBP})-(0.61 \times \mathrm{B})$

Where SD is the systolic discharge $(\mathrm{ml})$; $\mathrm{PP}-$ pulse pressure $(\mathrm{mmHg})$; DBP - diastolic blood pressure $(\mathrm{mmHg}) ; \mathrm{B}-$ age in years. The cardiac output was calculated by the formula:

Cardiac output $=$ systolic discharge $* \mathrm{HR} \mathrm{ml} / \mathrm{min}$.

Where SD is systolic discharge $(\mathrm{ml})$; HR - heart rate per minute (beats/min).

The Robinson index was calculated by the formula:

$\mathrm{RI}=\mathrm{HR} * \mathrm{SBP} / 100$, c.u.

Where HR is the heart rate per 1 minute, SBP is systolic blood pressure. RI value is equal to and less than 75 standard units is regarded as "above average," from 76 to 89 conventional units - "average," 90 and above - "below average."

IFC was calculated by formula:

$\mathrm{IFC}=0.011 \times \mathrm{HR}+0.014 \times \mathrm{SBP}+0.008 \times \mathrm{DBP}+$

$+0.014 \times \mathrm{B}+0.009 \times \mathrm{BW}-0.009 \times \mathrm{H}-0.27$.

Where HR is the resting heart rate (beats/min), SBP is systolic blood pressure ( $\mathrm{mm} \mathrm{Hg}$.), $\mathrm{DBP}$ - diastolic blood pressure (mm Hg.), B - age (years), BW - body weight $(\mathrm{kg}), \mathrm{H}-$ height $(\mathrm{cm})$. The value of IFC up to 2.6 characterizes the satisfactory operation of the circulatory system. The IFC indicator from 2.6 to 3.1 indicates a function load, from 3.1 to 3.5 - an unsatisfactory function, from 3.5 and above - a breakdown of the function of the circulatory system.

The level of physical condition according to E.A. Pirogova is calculated by the formula:

$\mathrm{LFC}=(700-3 \times \mathrm{HR}-2.5 \times$ APmean $-2.7 \times \mathrm{A}+0.28 \times \mathrm{M}) /(350-2.6 \times \mathrm{A}+0.21 \times \mathrm{H}), \quad$ (12)

Where $\mathrm{A}$ is age, years; $\mathrm{M}-$ body weight, $\mathrm{kg} ; \mathrm{H}-$ height, cm; APmean - mean arterial pressure, mm.Hg.; HR - heart rate, beats/min. Low $(<0.375)$, lower than average (0.376-0.525), medium (0.526-0.675), higher than average $(0.676-0.825)$ and high $(>0.826)$ LFC [5] were defined. The heart index is calculated using the formula:

$\mathrm{HI}=\mathrm{CO} / \mathrm{BSA}$.

The norm is values from 2.2 to $2.41 / \mathrm{min} / \mathrm{m}^{2}$. The hemodynamic types are determined by the HI value. At 
$\mathrm{HI}<2.7 \mathrm{l} / \mathrm{min} / \mathrm{m}^{2}$-hypokinetic type is established. At HI from 2.7 to $3.51 / \mathrm{min} / \mathrm{m}^{2}$-eukinetic, HI $>3.5$ $1 / \mathrm{min} / \mathrm{m}^{2}$-hyperkinetic hemodynamic types are established.

Statistical analysis of the obtained data was carried out using parametric and non-parametric methods by SPSS 17.0 application package. Characteristic distributions and estimation of distribution characteristics (minimum, maximum, average, standard deviation) are calculated. The assessment of intergroup differences was carried out by Mann-Whitney Ucriterion. To assess the intergroup differences of relative measures, Pearson's test $\chi^{2}$ was used. The differences were considered valid at $\mathrm{p}<0.05$ [6].

\section{RESULTS OF THE RESEARCH}

Patients' cards of the examined men revealed that $78.6 \%$ of men of the first mature age were practically healthy, $7.5 \%$ of men had gastrointestinal pathology, $4.7 \%$ - cardiovascular pathology, $4.1 \%$ - respiratory pathology. The remaining $5.1 \%$ of men had pathology of other organs (blood system, musculoskeletal system, benign neoplasms, allergic reactions, urinary system). The structure of diagnoses of men of the second mature age was as follows: almost healthy $-46.4 \%$, with the pathology of the cardiovascular system $-21.1 \%$, with the pathology of the gastrointestinal tract $-16.5 \%$, with the pathology of the respiratory system and musculoskeletal system $-4.0 \% .8 .0 \%$ of men of second maturity were diagnosed with diseases of other organs (urinary system, blood system, endocrine system, benign neoplasms, skin diseases and allergic reactions).

The anthropometric survey revealed that the body length of men of the first period of adulthood was $175.03 \pm 6.86 \mathrm{~cm}(175.0 \mathrm{~cm}[170.0 ; 180.0])$, body weight $-79.30 \pm 12.17 \mathrm{~kg}(78.0 \mathrm{~kg}[70.0 ; 87.0])$, BMI $25.84 \pm 3.39 \mathrm{~kg} / \mathrm{m} 2\left(25.43 \mathrm{~kg} / \mathrm{m}^{2}\right.$ [23.50; 28.03]). The somatometric parameters of men of the second mature age period were as follows: body length $-173.24 \pm 6.93 \mathrm{~cm}$ $(173.0 \mathrm{~cm}[168.75 ; 178.0])$, body weight $-85.49 \pm$ $14.18 \mathrm{~kg}(84.0 \mathrm{~kg}[75.0 ; 94.0])$, BMI $-28.41 \pm 3.94$ $\mathrm{kg} / \mathrm{m}^{2}(27.99 \mathrm{~kg} / \mathrm{m} 2$ [25.66; 30.66]). The analysis of the anthropometric parameters of the men of two age groups revealed significant differences $(p<0.001)$. In men of second maturity, a smaller body length value is observed at large body weight values and BMI. The average body surface area of men of the first mature age was $1.95 \pm 0.17 \mathrm{~m}^{2}$ (min-1.45 $\mathrm{m}^{2}$, $\left.\max -2.47 \mathrm{~m}^{2}\right)$. In the second mature age, the BSA was $2.02 \pm 0.19 \mathrm{~m}^{2}$ (min$1.49 \mathrm{~m}^{2}, \max -2.75 \mathrm{~m}^{2}$ ).

According to BMI value insufficient body weight was detected in 2 men $(0.7 \%)$ in the group of men of the first mature age period, normal body weight was determined in 131 men (44.4\%), excess weight in 129 (43.7\%), obesity in 33 men (11.2\%). Among men of the second mature age, insufficient body weight was determined in 1 man $(0.2 \%)$, normal body weight in 98 men $(19.5 \%)$, excess body weight in 253 (50.4\%), obesity - $150(29.9 \%)$. A significant BMI difference was identified $(\chi 2=71.182 ; p<0.001)$, the critical value of $\chi 2$ at the significance level $\mathrm{p}=0.01$ was 11.345). Insufficient body weight according to WHO recommendations is considered chronic energy deficiency. In the examined men, insufficient body weight was extremely rare. The prevalence of overweight and obesity among second-age men was alarming, as overweight and obesity were recognized risk factors for cardiovascular pathology.

The average value of SBP and DBP for men of the first group was equal to $121.33 \pm 10.12 \mathrm{~mm} \mathrm{Hg}$ and $79.47 \pm 6.53 \mathrm{~mm} \mathrm{Hg}$, respectively. Pulse pressure was $41.86 \pm 6.08 \mathrm{~mm} \mathrm{Hg}$, average pressure $-93.42 \pm 7.37$ $\mathrm{mm} \mathrm{Hg} \mathrm{HR}-73.10 \pm 8.22$ beats per 1 minute. Similar indicators for men of the second group were presented by the following averages: SBP $-129.78 \pm 18.04 \mathrm{~mm}$ $\mathrm{Hg}$, DBP $-84.16 \pm 9.95 \mathrm{~mm} \mathrm{Hg}$, pulse pressure -45.65 $\pm 10.65 \mathrm{~mm} \mathrm{Hg}$, average pressure $-99.36 \pm 12.22 \mathrm{~mm}$ $\mathrm{Hg}, \mathrm{HR}-74.90 \pm 8.98$ beats per $1 \mathrm{~min}$. Comparative analysis of the obtained parameters showed reliably $(\mathrm{p}<$ 0.001) high values of SBP, DBP, mean and pulse pressures in men of the second mature age period. The HR of patients of two groups was not significantly different $(p=0.067)$. The obtained indicators indicate age-related changes of vessel wall [7].

The autonomic regulation index showed that parasympathetic nervous system prevailed in both male groups (79.7 and $80.7 \%$, respectively). Sympathicotonia was detected in $16.9 \%$ of men of the first group and $14.5 \%$ of men of the second group. The equilibrium of the autonomic nervous system was determined in 3.4 and $4.8 \%$, respectively. No statistically significant differences were found in the distribution of the autonomic regulation index. According to research data, the predominance of the tone of the parasympathetic nervous system has a protective effect on the myocardium and assumes the functions of restoring and accumulating energy resources. Sympathetic department of autonomic nervous system is activator of functional capabilities of organism and performs adaptation-trophic function. [8, 9].

According to the Kwaas index, $70.5 \%$ of men of the first mature age and $62.5 \%$ of the second mature age had a busy loafers heart, a normal value was found in $27.1 \%$ and $30.3 \%$, enhanced heart function in $2.4 \%$ and $7.0 \%$, respectively. The predominance of patients with a busy loafers heart in both groups was alarming, as this might lead to the development of cardiovascular pathology in the future.

The normal circulatory efficiency ratio was found only in 2.0 and $1.2 \%$ of men in both groups. Low coefficient of profitability of blood circulation was 
recorded in $15.3 \%$ of men in the first group and $9.2 \%$ of men in the second group. High values characterizing cardiovascular fatigue were determined in most surveyed men $(82.7 \%$ in the first group and $89.6 \%$ in the second group).

The Robinson index is the most sensitive indicator of the energy potential of the cardiovascular system. According to the Robinson index, a low level (a decrease in the "reserve") was recorded in $49.5 \%$ in the first group and $62.5 \%$ in the second group. The average level of RI was determined in $34.2 \%$ in the first group and $29.3 \%$ in the second group. High RI values were found in 16.3 and $8.2 \%$, respectively.

The index of functional changes was in $77.3 \%$ of men in the first mature age and $25.1 \%$ in the second mature age was within the norm, which indicated a satisfactory function of the cardiovascular system. The stress of the functional capabilities of the cardiovascular system and regulatory systems of the body was determined in $21.0 \%$ of men in the first group and $46.8 \%$ of men in the second group. Unsatisfactory function and cardiovascular system dysfunction was observed in 1.0 and $0.7 \%$ of men of the first group. In the second group, these figures were significantly higher and amount to 18.9 and $9.2 \%$, respectively.

IFC analysis by E.A. Pirogova revealed an average level of physical condition in $60.3 \%$ of men of the first group and $33.7 \%$ of men of the second group. IFC values "below average" and "low" in men of the first group were found in 12.9 and $2.4 \%$. In men of the second group, these values were significantly higher ( 35.7 and $23.1 \%$, respectively). "Above average" and "high" IFC in the first group was recorded in 23.1 and $1.3 \%$. In the second group, "above average" $-7.2 \%$, "high" $-0.4 \%$, which was significantly lower than the indicators of the first group of men $(\chi 2=155.697$, $\mathrm{p}<0.001$; the critical value of $\chi^{2}$ at significance level $\mathrm{p}=0.01$ was 13.277 )

The average hemodynamic indicators of systolic discharge (44.82 \pm 5.65 in men of the first group, $45.71 \pm 7.13$ in men of the second group) and the cardiac index $(1.69 \pm 0.34$ and $1.70 \pm 0.37)$ did not have age-related features. The cardiac output indicator was significantly higher $(\mathrm{p}=0.029)$ in men of the second mature period and amounted to $3.42 \pm 0.68$ versus 3.27 \pm 0.60 . Mean values of indicators are shown in Table 1 , Table 2.

The type of hemodynamics of the examined men was determined by the HI value. In the first mature age, $99.32 \%$ had a hypokinetic type of hemodynamics, $0.68 \%$ - hyperkinetic. The eukinetic type was not detected in this age group. Among men of the second mature age, persons with the hypokinetic type also prevailed $(97.02 \%)$. The eukinetic type was determined in $2.19 \%$, hyperkinetic- $0.79 \%$ of the examined men.
Table 1. Mean value of cardiovascular indices of men of Yakutia of the first mature age

\begin{tabular}{|l|l|l|l|l|}
\hline Index & Min-m & Max-m & Mean & $\begin{array}{l}\text { Standard } \\
\text { Deviation }\end{array}$ \\
\hline $\begin{array}{l}\text { Autonomic } \\
\text { regulation index }\end{array}$ & -61.29 & 44.44 & -10.05 & 15.01 \\
\hline Kwaas index & 10.3 & 54.0 & 17.86 & 3.92 \\
\hline $\begin{array}{l}\text { Coefficient of } \\
\text { profitability of } \\
\text { blood circulation }\end{array}$ & 1500.0 & 7560.0 & 3062.55 & 607.01 \\
\hline $\begin{array}{l}\text { The systolic } \\
\text { discharge }\end{array}$ & 23.08 & 84.00 & 4482 & 5.65 \\
\hline Cardiac output & 1.73 & 9.07 & 3.27 & 0.60 \\
\hline Heart index & 0.89 & 4.52 & 1.68 & 0.34 \\
\hline Robinson's Index & 55.00 & 140.40 & 88.72 & 12.78 \\
\hline $\begin{array}{l}\text { Index of functional } \\
\text { changes }\end{array}$ & 1.70 & 3.67 & 2.43 & 0.26 \\
\hline $\begin{array}{l}\text { Physical condition } \\
\text { by E.A. Pirogova }\end{array}$ & 0.15 & 0.90 & 0.60 & 0.10 \\
\hline
\end{tabular}

Table 2. Mean value of cardiovascular indices of men of Yakutia the second mature age

\begin{tabular}{|l|l|l|l|l|}
\hline Index & Min-m & Max-m & Mean & $\begin{array}{l}\text { Standard } \\
\text { Deviation }\end{array}$ \\
\hline $\begin{array}{l}\text { Autonomic } \\
\text { regulation index }\end{array}$ & -75.00 & 54.55 & -13.61 & 16.96 \\
\hline Kwaas index & 7.5 & 36.7 & 17.16 & 4.02 \\
\hline $\begin{array}{l}\text { Coefficient of } \\
\text { profitability of } \\
\text { blood circulation }\end{array}$ & 1980.0 & 7600.0 & 3417.32 & 927.80 \\
\hline $\begin{array}{l}\text { The systolic } \\
\text { discharge }\end{array}$ & 27.27 & 84.00 & 45.71 & 7.13 \\
\hline Cardiac output & 2.09 & 7.20 & 3.42 & 0.68 \\
\hline Heart index & 0.93 & 4.38 & 1.70 & 0.37 \\
\hline Robinson's Index & 54.00 & 180.00 & 97.30 & 18.76 \\
\hline $\begin{array}{l}\text { Index of } \\
\text { functional } \\
\text { changes }\end{array}$ & 1.92 & 4.74 & 2.89 & 0.40 \\
\hline $\begin{array}{l}\text { Physical condition } \\
\text { by E.A. Pirogova }\end{array}$ & -0.19 & 0.95 & 0.47 & 0.16 \\
\hline
\end{tabular}


A comparative analysis of the morphofunctional parameters of men, depending on the type of hemodynamics and age period, was carried out only in the statistically predominant group of men with the hypokinetic type. The anthropometric and hemodynamic parameters of hypokinetic men are presented in tables 3 and 4. Statistically significant $(p<0.001)$ differences were found in all the studied indicators, with the exception of heart rate, systolic discharge, cardiac output and cardiac index.

Table 3. Morphofunctional parameters of hypokinetic men of the first mature age

\begin{tabular}{|c|c|c|c|c|}
\hline \multirow{2}{*}{ Index } & \multicolumn{4}{|c|}{ Hypokinetic type $(n=293)$} \\
\hline & Min-m & Max-m & Mean & $\begin{array}{l}\text { Standard } \\
\text { Deviation }\end{array}$ \\
\hline Body length & 150.00 & 198.00 & 175.04 & 6.87 \\
\hline Body weight & 43.00 & 120.00 & 79.29 & 12.19 \\
\hline $\mathrm{BMI}$ & 13.88 & 39.06 & 25.83 & 3.39 \\
\hline $\begin{array}{l}\text { Systolic blood } \\
\text { pressure }\end{array}$ & 80.00 & 170.00 & 121.27 & 10.13 \\
\hline $\begin{array}{l}\text { Diastolic blood } \\
\text { pressure }\end{array}$ & 60.00 & 100.00 & 79.50 & 6.42 \\
\hline Pulse Pressure & 20 & 70 & 41.77 & 5.87 \\
\hline $\begin{array}{l}\text { Average } \\
\text { Pressure }\end{array}$ & 66.7 & 123.3 & 93.43 & 7.35 \\
\hline Heart rate & 50.00 & 108.00 & 72.99 & 7.99 \\
\hline Kwaas index & 10.3 & 54.0 & 17.87 & 3.93 \\
\hline $\begin{array}{l}\text { Coefficient of } \\
\text { profitability of } \\
\text { blood } \\
\text { circulation }\end{array}$ & 1500.0 & 5600.0 & 3047.83 & 548.98 \\
\hline $\begin{array}{l}\text { The systolic } \\
\text { discharge }\end{array}$ & 23.08 & 60.00 & 44.71 & 5.17 \\
\hline Cardiac output & 1.73 & 5.02 & 3.26 & 0.50 \\
\hline Heart index & 0.89 & 2.67 & 1.67 & 0.30 \\
\hline $\begin{array}{l}\text { Robinson's } \\
\text { Index }\end{array}$ & 55.00 & 140.40 & 88.53 & 12.45 \\
\hline $\begin{array}{l}\text { Index of } \\
\text { functional } \\
\text { changes }\end{array}$ & 1.70 & 3.67 & 2.43 & 0.26 \\
\hline $\begin{array}{l}\text { Physical } \\
\text { condition by } \\
\text { E.A. Pirogova }\end{array}$ & 0.151 & 0.908 & 0.608 & 0.10 \\
\hline
\end{tabular}

Table 4. Morphofunctional parameters of hypokinetic men of the second mature age

\begin{tabular}{|c|c|c|c|c|}
\hline \multirow{2}{*}{ Index } & \multicolumn{4}{|c|}{ Hypokinetic type $(n=487)$} \\
\hline & Min-m & Max-m & Mean & $\begin{array}{l}\text { Standard } \\
\text { Deviation }\end{array}$ \\
\hline Body length & 154.00 & 192.00 & 173.31 & 6.96 \\
\hline Body weight & 47.00 & 153.00 & 85.57 & 14.16 \\
\hline BMI & 16.26 & 48.29 & 28.41 & 3.91 \\
\hline $\begin{array}{l}\text { Systolic blood } \\
\text { pressure }\end{array}$ & 90.00 & 210.00 & 129.30 & 17.54 \\
\hline $\begin{array}{l}\text { Diastolic blood } \\
\text { pressure }\end{array}$ & 60.00 & 130.00 & 84.19 & 9.92 \\
\hline Pulse Pressure & 25 & 100 & 45.10 & 9.90 \\
\hline Average Pressure & 70.0 & 150.0 & 99.23 & 12.10 \\
\hline Heart rate & 48.00 & 120.00 & 74.57 & 8.49 \\
\hline Kwaas index & 7.5 & 36.7 & 17.20 & 3.91 \\
\hline $\begin{array}{l}\text { Coefficient of } \\
\text { profitability of blood } \\
\text { circulation }\end{array}$ & 1980.0 & 7600.0 & 3363.26 & 841.31 \\
\hline The systolic discharge & 27.27 & 75.00 & 45.28 & 6.43 \\
\hline Cardiac output & 2.09 & 6.00 & 3.37 & 0.58 \\
\hline Heart index & 0.93 & 2.68 & 1.67 & 0.31 \\
\hline Robinson's Index & 54.00 & 180.00 & 96.55 & 18.01 \\
\hline $\begin{array}{l}\text { Index of functional } \\
\text { changes }\end{array}$ & 1.92 & 4.74 & 2.89 & 0.40 \\
\hline $\begin{array}{l}\text { Physical condition by } \\
\text { E.A. Pirogova }\end{array}$ & -0.190 & 0.953 & 0.477 & 0.15 \\
\hline
\end{tabular}

\section{CONCLUSION}

Thus, the overall body sizes analysis of men of the examined groups revealed a smaller value of body length at large body weight and BMI values in secondmature men. Excess body weight and obesity are significantly more often recorded also in those of second maturity. Hemodynamic indicators of second mature men were characterized by higher values of SBP, DBP, mean and pulse pressures, cardiac output. The autonomic regulation index analysis showed that both male groups were dominated by individuals with vagotonia. The assessment index of the cardiovascular system revealed: $70.5 \%$ of men of the first mature age and $62.5 \%$ of the second mature age had a drained heart by Kwaas index; most patients had high coefficient of profitability of blood circulation; a low level (a decrease in the "reserve") was recorded in $49.5 \%$ in the first 
group and $62.5 \%$ in the second group by Robinson index. In both groups studied, individuals with hypokinetic type of hemodynamics prevailed. A comprehensive assessment of the level of functional state according to IFC and physical development by Pirogovaya E.A. revealed satisfactory functioning and normal level of physical state of the body in most men in the first mature age. Men of second maturity had lower rates of functional status and physical development.

Individuals with a detrained heart, high coefficient of profitability of blood circulation, low Robinson index, high BMI, and high blood pressure values are at risk for the onset of cardiovascular pathology and need systematic medical control.

\section{REFERENCES}

[1] Federal State Statistics Service (Yakutia). Retrieved from: https://sakha.gks.ru/folder/32348

[2] S.A. Boytsov, O.M. Drapkina, Therapeutic Archive, 93(1) (2021) 4-6.

[3] A.M. Kalinina, G.E. Sokolov, B.E. Gorny, O.M. Drapkina, Prevent. Med. 24(1) (2021) 26-34.

[4] E.N. Brudnaya, I.F. Ostapchuk, Methods of functional diagnosis of the cardiovascular system, Zdorov's, Kiev, 1988.

[5] V.A. Colleda, Physical culture, Tesey, Minsk, 2019.

[6] A. Petri, K. Sabin, Visual Medical Statistics, GEOTAR-Media, Moscow, 2015.

[7] O.P. Rotar, A.S. Aliyev, M.A. Barinov et al., Cardiol. 59(2) (2019) 45-53.

[8] A.V. Demin, A.V. Suvorov, A.I. Orlov, Aerosp. and environ. Med. 55(2) (2021) 63-68.

[9] E.Yu. Shalamova, O.N. Ragozin, V.P. Safonov, Hum. Ecol. 6 (2016) 26-32. 